\title{
Fine needle aspiration cytology of giant chondroid hamartoma of lung with review of literature.
}

\author{
${ }^{1}$ Dr. Manisha Mahata, ${ }^{2}$ Dr. Sambit Dasgupta* ${ }^{3}$ Dr. Suman Ghosh, ${ }^{4}$ Dr. Soumita \\ Ghosh Sengupta, ${ }^{5}$ Prof. Ranu Sarkar, ${ }^{6}$ Prof. Jayati Chakrabarty \\ ${ }^{1,2} M D$ (Path), Demonstrator Acquisition of data, analysis and interpretation of data, drafting the article, revising \\ it critically for important intellectual content, final approval of the version to be published \\ ${ }^{3.4 .5} \mathrm{MD}$ (Path), Assistant Professor Analysis and interpretation of data, revising it critically for important \\ intellectual content final approval of the version to be published. \\ ${ }^{6} \mathrm{MD}$ (Path), Professor Analysis and interpretation of data, revising it critically for important intellectual content \\ final approval of the version to be published.
}

\begin{abstract}
Giant pulmonary hamartoma (diameter $>9 \mathrm{cms}$ ) is a very uncommon benign tumor with only eleven reported cases. Here we report such a rare case of giant pulmonary hamartoma measuring $12 \mathrm{cms}$ in diameter occupying almost whole of the left hemithorax. CT guided FNAC was done in suspicion of a malignant tumor but the cytomorphological features were of a benign cartilaginous neoplasm. The cytological findings were correlated with the radiological features and a diagnosis of chondroid hamartoma was suggested on FNAC. The diagnosis was later confirmed by histopathological examination.
\end{abstract}

Key Words: lung, giant chondroid hamartoma, fine needle aspiration cytology

\section{Introduction}

Pulmonary hamartoma, also known as chondroma, chondroid hamartoma, chondroid adenoma, mesenchymoma, is the most common type of benign lung tumours, composed of varying proportions of mesenchymal tissues with entrapped respiratory epithelium. They were considered as developmental abnormalities in the past but now considered as benign mesenchymal neoplasms. ${ }^{[1-5]}$

Incidence of pulmonary hamartoma is $0.25 \%$ with a two to four fold male preponderance, most occurring in $6^{\text {th }}$ decade of life. Most often it is incidentally discovered as solitary nodule on chest $\mathrm{x}$-ray. ${ }^{[1,2,3]}$ They are usually peripheral and less than $5 \mathrm{~cm}$ in diameter. Giant pulmonary hamartoma ( measuring $>9 \mathrm{~cm}$ in diametre ) is very rare and only 11 cases have been published till date ${ }^{[6-13]}$. Here we present a 27 years old female with a giant chondroid hamartoma, measuring $12 \mathrm{cms}$ in diametre extending from periphery to bronchus, in the left lung.

\section{Case Report}

A 27 year old female was admitted to our hospital with cough, fever, and left-sided chest pain of 8 months duration. She had an episode of haemoptysis. Physical examination revealed decreased breath sounds in the left side. Routine blood and biochemical parameters were within normal limits. Sputum was negative for acid-fast bacilli.

X-ray revealed a large homogeneous opacity occupying almost whole of the left hemithorax blurring the left C-P angle. CT-scan (Figure 1) confirmed a large, heterogeneous mass measuring $12 \mathrm{cms}$ in diameter occupying almost entire left hemithorax with extensive nodular (popcorn) calcification. Mediastinum was displaced to right. Left bronchus was compressed. No mediastinal lymphadenopathy or pleural effusion was documented. Radiological impression suggested a malignant neoplasm.

CT-guided FNAC of the lesion was done. Smears were stained by May-Grünwald-Giemsa and Papanicolaou (Pap) stains. Smears were moderately cellular comprising of round to ovoid cells with nucleomegaly and anisonucleosis, moderate amount of pale cytoplasm in a fibromyxoid background. There were also sheets of broncholiolar epithelium interspersed with fat cells and with foci of calcified spherules (Figure 2). Based on cytology a strong suspicion of chondroid hamartoma was made.

Percutaneous transthoracic needle biopsy, the main diagnostic approach, showed predominantly cartilaginous tissue \& confirmed the diagnosis (Figure 3A, 3B, 3C ).

Endobronchial biopsy showed immature cartilaginous cells having acidophilic cytoplasm that resemble histiocytes along with plump fibroblast \& smooth muscle fibres (Figure 3D, 3E).

The patient is on follow-up and awaiting surgery. 


\section{Discussions}

The term "hamartoma" was coined by Albrecht ${ }^{[14]}$ in 1904 to describe tumor-like malformations resulting from a presumptive developmental abnormality. In 1934, Goldsworthy ${ }^{[15]}$ applied this term to benign lung tumors which were composed predominantly of a combination of fat and cartilage. Cytogenetic studies have identified chromosomal bands of recombination located at $6 \mathrm{p} 21$ and 14q24 positions which supports the theory that hamartomas represent mesenchymal clonal neoplasms. ${ }^{[16]}$

Pulmonary hamartomas are the most common benign tumours of the lung. While most of the usual hamartomas measure $1-5 \mathrm{~cm}$ in diameter, giant hamartomas reported measure between 9 to $30 \mathrm{~cm} .{ }^{[1,3,6]}$ Petheram and colleagues reported a massive hamartoma with a diameter of $30 \mathrm{~cm} .{ }^{[6]}$ Most of the giant hamartomas are seen in female patients in contrast with the usual hamartomas which have a male preponderance. The age of presentation is wide -30 to 63 years, mean age being 48.9 years. Some of the patients are younger than the expected age. Most of the giant hamartomas reported are localized in the right lung. Our patient is a 27-year-old female with a giant hamartoma in the left lung with endobronchial extension.

The peripheral pulmonary hamartomas are usually asymptomatic. Occasionally, the tumors are central or giant with endobronchial extension causing hemoptysis, bronchial obstruction, coughing, wheezing, expectoration, leukocytosis and fever. Our patient also presented with cough, fever, and chest pain of 8 months duration and an attack of hemoptysis due to the giant size of the tumor with compression of bronchus and endobronchial extension.

Usually diagnosis of hamartomas are incidental. These tumors constitute about $8 \%$ of all "coin" lesions in chest radiograph ${ }^{[17]}$. X-ray shows solitary well-defined pulmonary nodules with varying patterns of calcification like irregular popcorn, stippled, or curvilinear pattern or even a combination of all three. In CT scan specific popcorn-type calcification seen in about $30 \%$ cases is almost pathognomonic. ${ }^{[1-4,11]}$. Our case has also typical popcorn calcification.

Fine needle aspiration cytology is diagnostic of majority of chondroid hamartomas $(90 \%)$ and hence widely used. ${ }^{[9,18]}$ Cytological criteria for diagnosis is presence of mature cartilage, myxoid connective tissues, sheets of bronchiolar epithelium \& adipose tissue. Sometimes anisonucleosis \& large intranuclear inclusion may lead erroneous diagnosis of malignancy. ${ }^{[1,2,8]}$

The histology of the parenchymal lesions in both giant and usual hamartomas usually reveals a predominant chondroid differentiation (80\%), with fibroblastic (12\%), fatty $(5 \%)$ and osseous (3\%) differentiation making the rest. ${ }^{[1,2]}$ Endobronchial lesions tend to have more fat. ${ }^{[6]}$ Myxomatous connective tissue, smooth muscle, blood vessels and other mesenchymal elements may also be seen histologically. ${ }^{[1,2]}$

Hasen and associates observed that preoperative diagnosis from transthoracic needle aspiration biopsy could be obtained in $85 \%$ of the patients with pulmonary harmatomas. ${ }^{[18]}$

Most tumors grow slowly (average of 3 mms per year) during follow-up. Surgical treatment is the gold standard in intraparenchymal hamartomas including enucleation, lobectomy or sleeve resection, wedge resection, segmentectomy and pneumonectomy. ${ }^{[18]}$

This case is being reported because of its rarity.

\section{References}

[1]. Van den Bosch J, Wagenaar S, Corrin B, et al. Mesenchymoma of the lung (so-called hamartoma): A review of 154 parenchymal and endobronchial cases. Thorax 1987;42:790-3.

[2]. Gjevre J, Myers J, Prakash U. Pulmonary hamartomas. Mayo Clin Proc 1996; 71:14-20.

[3]. Tomashefski J Jr. Benign endobronchial mesenchymal tumors: Their relationship to parenchymal pulmonary hamartomas. Am J Surg Pathol 1982; 6:531-40.

[4]. Bateson EM. So-called hamartoma of the lung-a true neoplasm of fibrous connective tissue of the bronchi. Cancer 1973;31:145867.

[5]. Tallini G, Vanni R, Manfioletti G, et al. HMGI-C and HMGI(Y) immunoreactivity correlates with cytogenetic abnormalities in lipomas, pulmonary chondroid hamartomas, endometrial polyps and uterine leiomyomas and is compatible with rearrangement of the HMGI-C and HMGI(Y) genes. Lab Invest 2000;80:359-69.

[6]. Petheram IS, Heard BE. Unique massive pulmonary hamartoma. Case report with review of hamartoma treated at Brompton Hospital in 27 years. Chest 1979;75:95-7.

[7]. Kervancioglu R, Bayram MM, Elbeyli L. Giant pulmonary hamartoma. Am J Roentgenol 1997;168:573.

[8]. Fujino S, Tezuka N, Sawai S, et al. Giant hamartoma of the lung. Jpn J Thorac Cardiovasc Surg 1998; 46:1229-31.

[9]. Lee SY, Park HJ, Lee CS, et al. Giant pulmonary hamartoma. Eur J Cardiothorac Surg 2002;22:1006.

[10]. Kim GY, Han J, Kim DH, et al. Giant cystic chondroid hamartoma. J Korean Med Science 2005;20:509-11.

[11]. Park JH, Kim MY, Hwang YJ, et al. Radiologic findings of giant pulmonary chondromatous hamartoma. J Korean Radiol Soc 2005;53:13-7.

[12]. Hutter J, Weinberger SR, Hutarew G, et al. Giant pulmonary hamartoma-a rare presentation of a common tumor. Ann Thorac Surg 2006;82:5-7.

[13]. Ganti S, Milton R, Davidson L, et al. Giant pulmonary hamartoma. J Cardiothorac Surg 2006;1:19.

[14]. Albrecht E. Ueber hamartome. Verh Dtsch Ges Pathol 1904;7:153-7.

[15]. Goldsworthy NE. Chondroma of lung (hamartoma chondromatosum polmonis), with report of case. J Pathol Bacteriol 1934; 39:291-8. 
Fine needle aspiration cytology of giant chondroid hamartoma of lung with review of literature.

[16]. Fletcher JA, Pinkus GS, Donovan K, Naeem R, Sugarbaker DJ, Mentzer S, et al. Clonal rearrangement of chromosome band 6p21 in the mesenchymal component of pulmonary chondroid hamartoma. Cancer Res 1992; 52 (22): 6224- 8 .

[17]. Toomes H, Delphendahl A, Manke HG, et al. The coin lesions of the lung. A review of 955 resected coin lesions. Cancer 1983;51:534-7.

[18]. Hansen CP, Holtveg H, Francis D, Rasch L, Bertelsen S. Pulmonary hamartoma. J Thorac Cardiovasc Surg 1992;104: 674-8.

\section{Figures:}

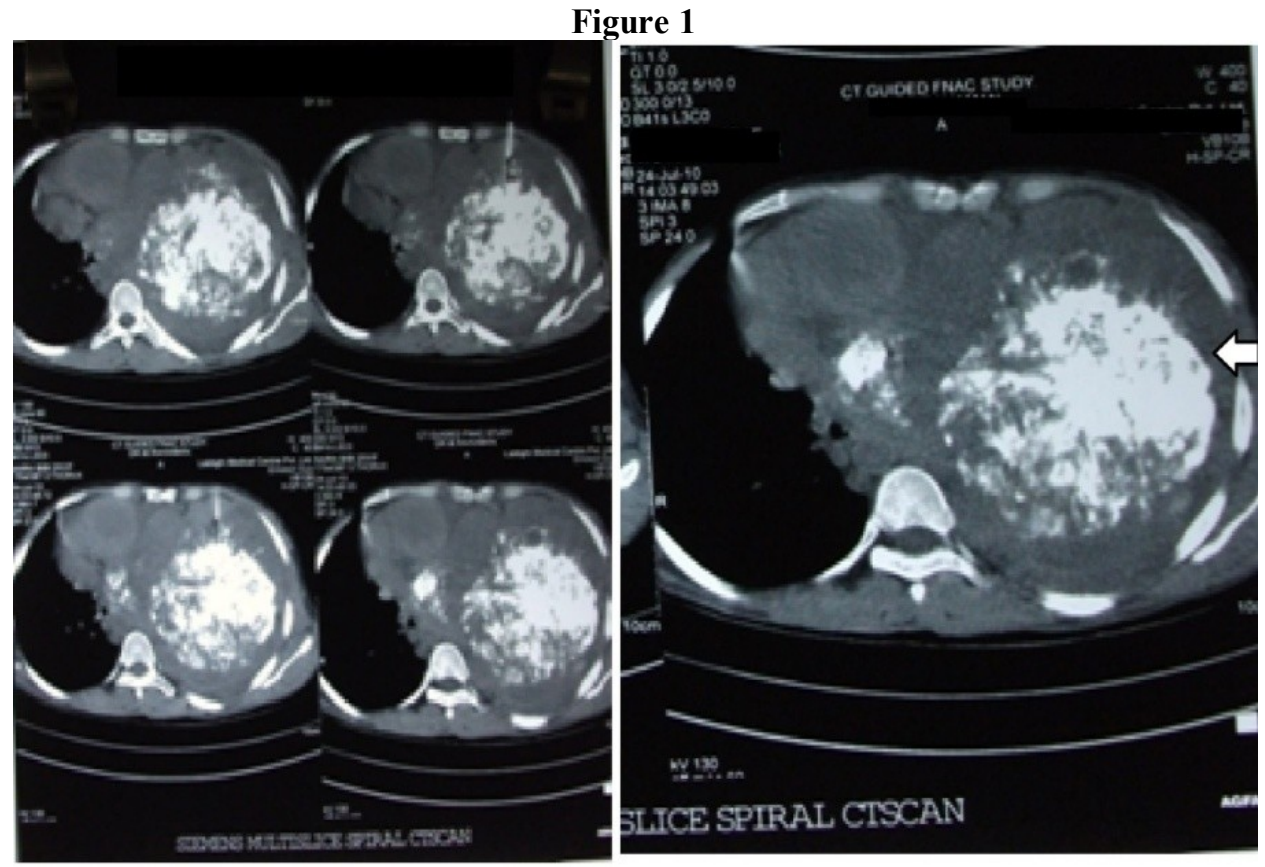

\section{Figure 2}

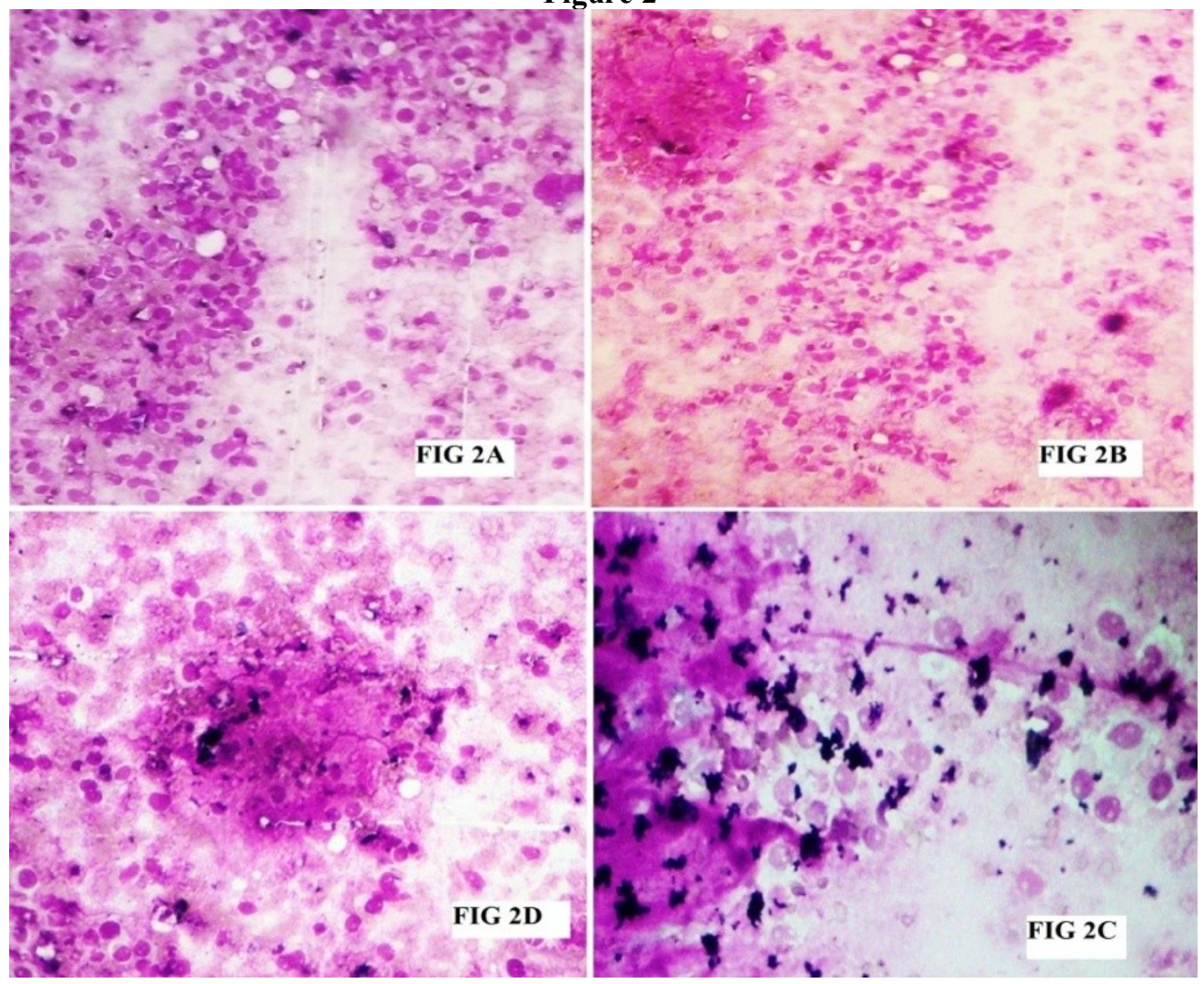




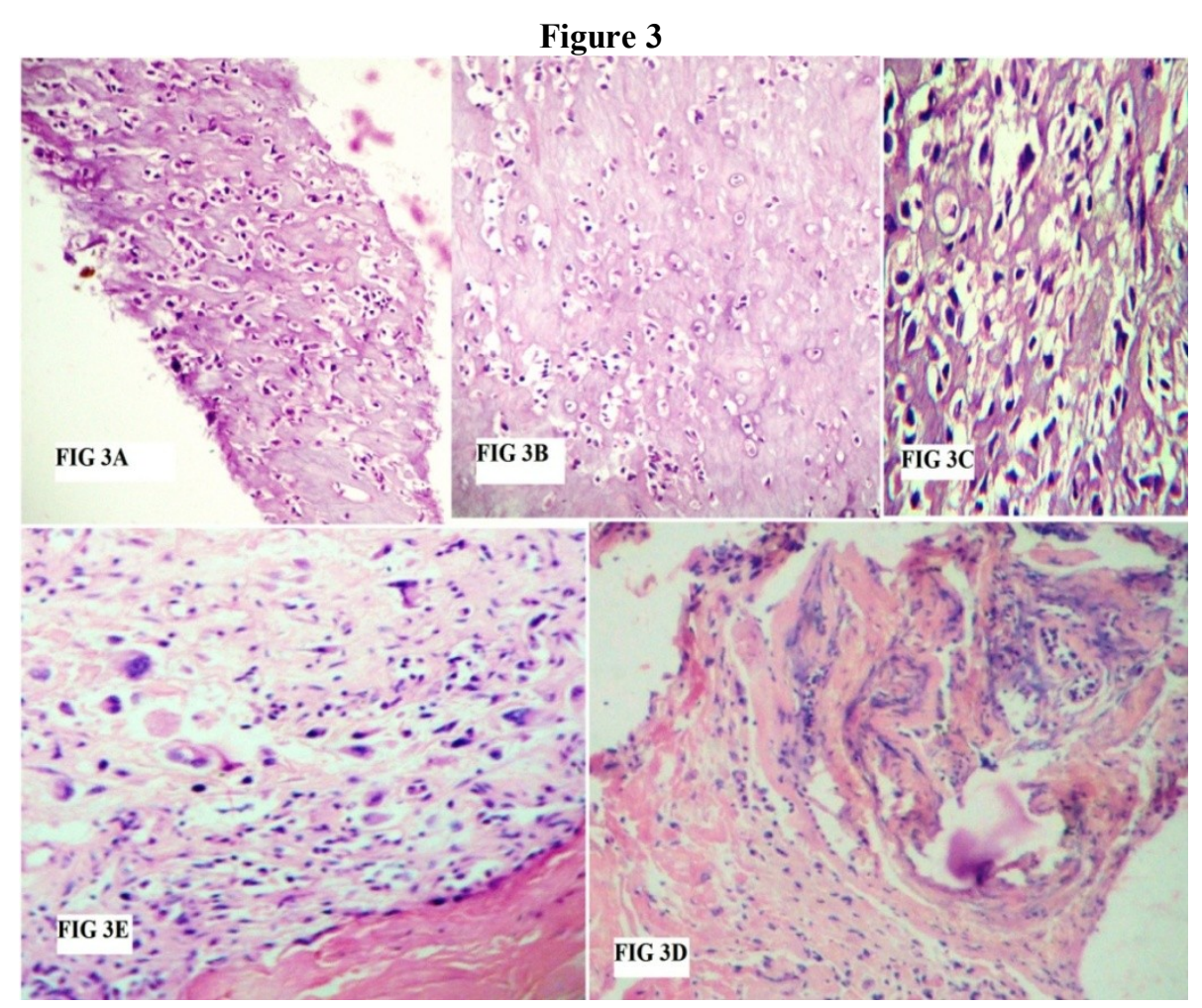

\section{Legend to Figures:}

Figure 1: . CTscan- large, heterogeneous mass occupying left hemithorax with extensive nodular (popcorn) calcification.

Figure 2: FNAC smears- moderately cellular with round to ovoid cells showing nucleomegaly and anisonucleosis, moderate amount of pale cytoplasm in a fibromyxoid background with foci of calcified spherules

Figure 3: Figure 3A, 3B, 3C- Percutaneous transthoracic needle biopsy showing predominantly cartilaginous tissue ; Figure 3D, 3E -Endobronchial biopsy showing immature cartilaginous cells having acidophilic cytoplasm that resemble histiocytes along with plump fibroblast $\&$ smooth muscle fibres. 